\title{
Compound actuation system design for an advanced space transportation reusable orbiter
}

\begin{abstract}
The SL-12 is a reusable space orbiter which offers the capability to go beyond the notion of a second generation space shuttle, and is targeted to be in operation in the year 2020. SL-12 Orbiter utilizes gimballing of the main rocket engines for control during ascent and typical aerodynamic surfaces for control during re-entry, approach, and landing. Power by wire (PBW) Actuation system is used for SL-12 based on All Electric Aircraft (AEA) approach. Electro Hydrostatic Actuators have been used for Primary Flight Control surfaces (Elevon, Body Flap and Rudder) and Thrust Vector Control for Main Engine Module, Electro Mechanical actuators have been used for Thrust Vector Control of Orbital Maneuvering System and Payload bay door. Dual redundant electric power supply channels are used for redundancy. Actuation System Safety and Reliability analysis has been done to ensure compliance and specification requirements.
\end{abstract}

Volume 2 Issue 5 - 2018

\author{
Amir Shahneh \\ Lecturer, School of Engineering, Cranfield University, England
}

Correspondence: AZ Shahneh, Lecturer, School of Engineering, Cranfield University, Bedford, England, MK43 OAL, Tel 0I23475460I,Email a.shahneh@cranfield.ac.uk

Received: August 07, 2018 | Published: September II, 2018
Abbreviations: PBW, power by wire; AEA, all electric aircraft; EHA, electro hydrostatic actuator; EMA, electro mechanical actuator; FHA, functional hazard analysis; FMECA, failure mode effects and criticality analysis; GDP, group design project; MEM, main engine module; NASA, national aeronautics and space administration; OMS, orbital maneuvering system; PFCS, primary flight control system; APU, auxiliary power unit; RVA, rotary vane actuator; DTLA, dual tandem linear actuator.

\section{Introduction}

The SL-12 is an under design reusable space orbiter which offers the capability to go beyond the notion of a second generation space shuttle, and is targeted to be in operation in the year 2020. The concept of SL-12 is based upon initial study of different reusable space vehicles such as X-37B and Shenlong Space Plane. As per project specifications, SL-12 is to be designed as a Modular orbiter vehicle to be able to fulfil a wide range of operational needs. It should be capable of taking a payload into Low Earth Orbit (LEO) to maintain International Space Station (ISS), carrying and launching satellites, making a low ' $\mathrm{g}$ ' return flight to Earth and making a conventional horizontal landing. Hence, SL-12 Orbiter is a combination of spacecraft and aircraft which can remain in orbit and also fly horizontally and land on existing commercial airport runways. The vehicle utilizes gimballing of the main rocket engines for control during ascent and typical aerodynamic surfaces for control during re-entry, approach, and landing. The orbiter can be launched using an expendable launch vehicle such as the Delta IV system or Atlas V system. It can be operated remotely from either the ground station or space station or it can operate in a number of autonomous modes. Missions will be of short duration of the order of 24 hours unless berthed with a space station. ${ }^{1}$ The primary certification requirements contained in NASA SP-8057 have been considered for the structural design. In this Group Design Project, author has designed all the Actuators and complete actuation system of this Orbiter. Actuation System architecture for a Reusable Orbiter is similar to the Actuation system of a Space Shuttle with the difference of power by wire actuation system consisting of electro hydrostatic and electro mechanical actuators. Main function of actuation system during various flight phases of Orbiter is to provide attitude control in three directions i.e. pitch, roll and yaw. During the launch or Ascent phase, Orbiter is controlled by engines that rotate about a gimbal. During Re-entry phase this control is achieved by control surfaces rotating about a hinge. The purpose of the actuation system is to provide the force that is needed to gimbal the engine or to rotate the aerodynamic-surfaces in the direction needed to control the Orbiter.

\section{Actuation system requirements of SL- | 2}

On the basis of commands from FCS, Thrust Vector Control (TVC) Actuators control the Orbiter during lift off and first stage ascent. Thrust for Orbital insertion, orbit transfer and de-orbiting is provided by the Orbital Maneuvering System (OMS). The OMS is housed in 2 pods located left and right side of the aft fuselage. These pods known as OMS/RCS pods also house the aft Reaction Control System (RCS). Each OMS engine has 2 EMA gimbal Actuators to control the thrust direction of OMS Engine in pitch and yaw (TVC). For a single-OMSengine thrusting period, control by RCS is required for rolling. The pitch and yaw actuators have identical specifications except stroke length which are operated by redundant electrical channels. The main and the most obvious function of actuation system, is to control the orbiter movement in three directions i.e. roll, pitch, yaw during the reentry phase. To control the orbiter in Earth's atmosphere, aerodynamic control surfaces that are Elevons, Body Flap, Normal Rudder and Split Rudder are deflected into the airstream. ${ }^{2}$ The Airworthiness Certification requirements are actually a part of Non-functional requirements which do not directly influence system operation but significant in terms of system's scope of work. As per Project Specification, the Orbiter has been designed to meet primary design requirements contained in NASA SP-8057. Further, SL-12 Orbiter needs to satisfy Certification Specification CS-25 applicable for large aircraft. Hence the Actuators have been designed in accordance with the strength of materials requirements of MMPDS-01, NASA SP$8057, \mathrm{CS}-25$ and project specification requirements. ${ }^{3,4,5}$

\section{SL- 12 actuation system details}

After a detailed trade-off study of types of actuation system options, the Power by wire concept (EHA and EMA) was selected by 
author over the hydraulic blowdown concept (used on NASA Space Shuttle [2]) as the means of actuation system for SL-12. Use of the EHA and EMA design in lieu of the more conventional hydraulic actuators for engine gimbaling dictates advancement in latest technology, less maintenance, high efficiency as well as cost saving. Proper redundancy considerations have been applied for selecting number of actuators per control surface. As per the requirements of primary flight control, every PFCS is equipped with at least two EHAs. Distribution of actuators for various functions during various stages of the orbiter is shown in Table 1.

Table I Distribution of actuators for various stages

\begin{tabular}{|c|c|c|c|}
\hline Stage/Phase & Actuator & $\begin{array}{l}\text { No of } \\
\text { actuators }\end{array}$ & $\begin{array}{l}\text { Type of } \\
\text { actuators }\end{array}$ \\
\hline Launch, Ascent & TVC for MEM & $1 \times 2$ & EHA (Linear) \\
\hline Ascent & $\begin{array}{l}\text { Folding Wing } \\
\text { Actuator }\end{array}$ & $2 \times 2$ & $\begin{array}{l}\text { Pneumatic } \\
\text { (Linear) }\end{array}$ \\
\hline Orbit & $\begin{array}{l}\text { Payload Bay } \\
\text { Door Actuator }\end{array}$ & $2 \times 2$ & EMA (Rotary) \\
\hline $\begin{array}{l}\text { Orbital Insertion/ } \\
\text { De-orbiting }\end{array}$ & TVC for OMS & $2 \times 2$ & EMA (Linear) \\
\hline $\begin{array}{l}\text { Re-Entry, } \\
\text { Approach, Landing }\end{array}$ & $\begin{array}{l}\text { Flight Control } \\
\text { Actuators: } \\
\text { - Elevon } \\
\text { - Body Flap } \\
\text { - Normal } \\
\text { Rudder/ } \\
\text { Split Rudder }\end{array}$ & $\begin{array}{l}2 \times 3 \\
1 \times 3 \\
2 \times 2\end{array}$ & $\begin{array}{l}\text { EHA (Linear) } \\
\text { EHA (Linear) } \\
\text { EHA (Rotary) }\end{array}$ \\
\hline
\end{tabular}

\section{Actuation system architecture}

As per Architecture of Actuation system, all primary flight control EHAs have been supplied with electrical power, 270VDC. Actuation architecture is based on dual redundancy of electrical channels. A separate DC bus is utilized to cater for power requirement of PFCS during re-entry phase. Further there is a provision of Auxiliary Power Unit (APU) for providing high peak power of $42 \mathrm{~kW}$ during the reentry phase when all primary flight control surfaces are operative. Due to better stress distribution and higher loads acting, author has decided to use three linear EHAs on Body flap as well as both Elevons, whereas two rotary EHAs have been installed on both the Rudders. Figure 1 shows the actuation system architect of Reusable Orbiter SL-12.

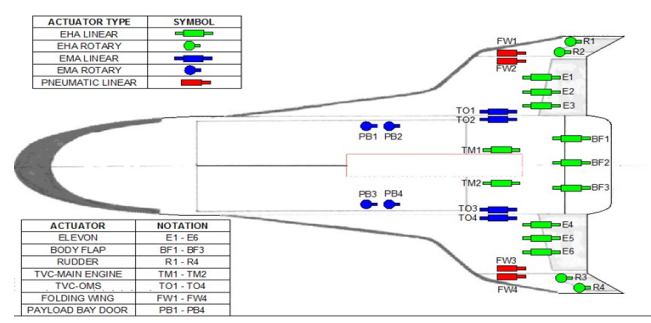

Figure I Actuation system architecture of SL- 12 orbiter.

Based on the study of NASA system architect, ${ }^{2}$ the author has prepared actuation system architect for SL-12 Orbiter considering all the requirements of actuation already established on the Space Shuttle. There are a few differences based on the requirements like Space Shuttle has 3 main engines whereas SL-12 orbiter has only one main engine module leading to lesser number of TVC Actuators for MEM. All Primary Flight Control Surfaces are to be operated by
Jam free EHAs. Pitch and Roll control is obtained by six independent Duplex EHA packages, 3 on LH side Elevon and 3 on RH side Elevon. In case of failure of one EHA, other actuators can operate the Elevon with obviously less load authority. Yaw control can be obtained by 2 simultaneously operated Rotary Vane EHAs on two Rudders by normal functioning of rudders, whereas air brake functioning is obtained by same rotary EHAs operating in opposite directions and working as Split Rudders. Body flap is operated by 3 Dual Tandem Linear EHA's and TVC Actuator for Main Engine Module is to be operated by 2 Double Rod End Linear EHA's one each for pitch and yaw. 4 Electromechanical Linear Actuators are used for Thrust Vector Control of Orbital Maneuvering System (2 for each nozzle) and 4 Electromechanical Rotary Actuators are used for Payload bay door actuation. Further Folding wings are operated by 4 Pneumatic Linear Actuators of Single acting type.

\section{Flight control system of SL- 2 orbiter}

Functional requirements for FCS have been derived from project specification, CS25 and NASA SP 508. The Flight Control Computer (FCC) system design is based on quadruple redundant FCC. The 4 FCCs will all compute the required thrust requirement from the control law and through comparison of the output and an implemented voting system, one set of output will be transmitted to the actuation systems to implement the required maneuvers.

\section{Actuation system safety and reliability}

Reliability analysis of the actuators has been performed using FMECA. The failure mode and effects portion of this analysis has been prepared in accordance with ARP $926^{6}$ and CS 25.1309. FHA and FTA have been conducted during the initial stages of actuation system development for SL-12 orbiter in accordance with ARP 4761 . The failure conditions have been identified, classified and associated with Orbiter's functions. FHA has been conducted for all primary flight control surface movements. Failure of actuation system for any one control surface lies in the 'level B extreme remote category' as the control surfaces on SL-12 Orbiter are jointly controlling the attitude in Pitch, Roll and Yaw. Fault tree diagrams for FTA have been generated using the software PTC Windchill Quality solutions. FTA for Body Flap is shown in Figure 2 for Illustration.

\section{Actuation system loading calculations}

The Angular strokes have been provided for flight control surfaces in the project specification requirements. ${ }^{1}$ So using simple trigonometry and geometrical calculations, author evaluated the corresponding linear stroke values wherever required. Load and Torque requirements acting on the Hinge locations of Flight Control Surfaces were evaluated along with the respective Surface designers. Load and stroke calculated are shown in Table 2.

\section{Actuation system power requirements}

Considering the flight control surfaces' deflection rates from NASA document, ${ }^{8}$ power calculations were conducted with loads already available. Detailed power calculations were conducted to establish phasewise power requirements for the orbiter. Peak power requirement of $42 \mathrm{~kW}$ was observed for short phase of 45 minutes during Re-entry of the orbiter. The provision of APU was made to satisfy this peak power requirement for short phase. Average power and emergency power requirements were also conducted based on 8020 rule $^{9}$ and emergency power calculated was $15 \mathrm{~kW}$. Li-Ion batteries were provisioned for satisfying this emergency power requirement. 


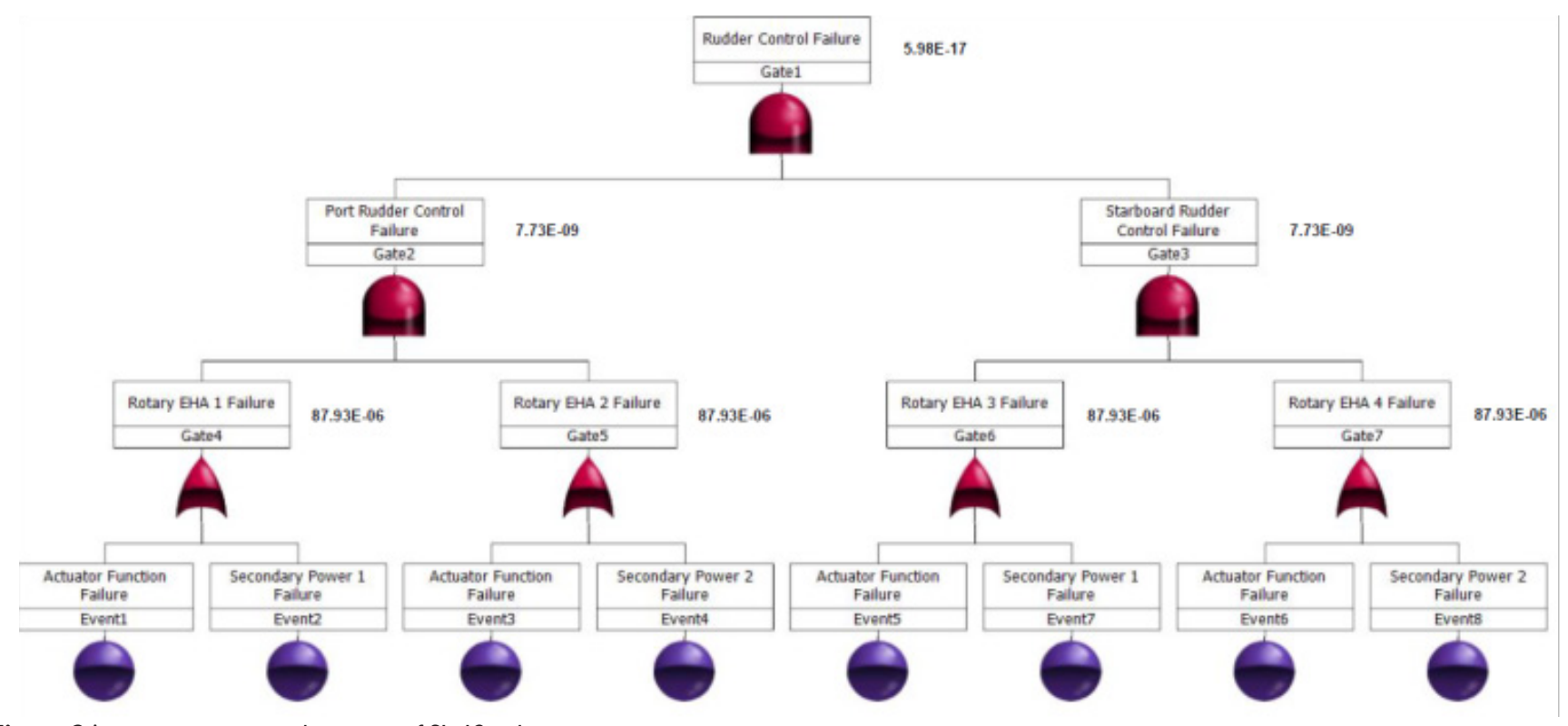

Figure 2Actuation system architecture of SL-12 orbiter.

Table 2 Load and stroke requirements for actuators

\begin{tabular}{lll}
\hline Actuator & Limit Load/ torque & Stroke (Angular/Linear) \\
\hline TVC for MEM & $1 \mathrm{lkN}$ & $\pm 12^{\circ}(192 \mathrm{~mm})$ \\
Folding Wing Actuator & $70 \mathrm{kN}$ & $57^{\circ}(125 \mathrm{~mm})$ \\
Payload Bay Door Actuator & $4 \mathrm{kN}-\mathrm{m}$ & $82.6^{\circ}$ \\
TVC for OMS & $1.67 \mathrm{kN}$ & $\pm 8^{\circ}(110 \mathrm{~mm})$ \\
Flight Control Actuators: & & \\
$-\quad$ Elevon & $124.27 \mathrm{kN}$ & $\pm 40^{\circ}(110 \mathrm{~mm})$ \\
$-\quad$ Body Flap & $133.8 \mathrm{kN}$ & $-20^{\circ} /+30^{\circ}(-60 /+90 \mathrm{~mm})$ \\
\hline$\quad$ Normal/ Split Rudder & $1.283 \mathrm{kN}-\mathrm{m}$ & $\pm 40^{\circ}$ \\
\hline
\end{tabular}

\section{Detail design of actuation system}

Design of all critical components of EHA was carried out, in order to make sure that all actuators integrate properly with the structure and do not stick out from the wing, fin, fuselage or any other structure. A very much standard approach was followed for detail design of Cylinder, Piston Rod and other critical components of power actuator. As Limit Load and operating pressure is known, so by considering a reasonable value for the ratio of Piston Rod diameter to Cylinder Inner diameter, all other dimensions are calculated using Cranfield Stressing data sheets. ${ }^{10}$

\section{Elevon actuator}

EHA of type Duplex Parallel Actuator Package has been used for actuation of Elevon. Duplex package is formed by connecting two double rod end actuators in parallel. By this package double load can be handled with same length however width of actuator system increases but by proper mounting of common Motor-pump unit, ACE \& Accumulator the width is also kept in proper check and total weight of unit was also effectively managed. This new concept of parallel actuation package has been used due to very less space available between Elevon spar and Wing spar where Elevon actuator is supposed to be mounted. Due to this small space lengthwise, a bigger hole in the spar to pass actuator piston could not be avoided so decision was made to use Duplex parallel actuators so that diameter of piston halved making diameter of spar hole in the limit of $40 \mathrm{~mm}$ diameter allowed by SL-12 Wing designer. CAD model for single power Actuator portion of Elevon actuator package is shown in Figure 3 for illustration with critical components marked. End Fitting and Rod End are main load carrying components. Spherical Bearings are used in both End Fitting and Rod End to mount on the Lugs of Wing and Elevon respectively. So End fitting remains fixed on Wing and by the movement of piston inside the cylinder due to hydraulic pressure, the Rod end moves to execute extension and retraction of actuator resulting in the deflection of Elevon. Further a displacement sensor (LVDT) is mounted inside the Piston to provide feedback of actuator movement to the Actuator Control Electronics unit. T-Seals have been used on Piston heads and inside the gland for dynamic sealing application. Static O-Rings are used on Gland to prevent external leakage. Scrapers rings are also used on Gland to prevent ingress of dirt in to the cylinder.

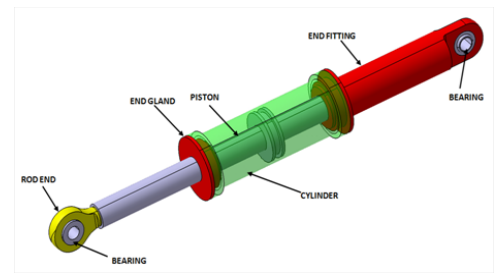

Figure $3 C A D$ model of elevon power actuator. 


\section{Body flap actuator}

EHA of type Dual Tandem Linear Actuator (DTLA) has been used for actuation of Body Flap. DTLA is simply formed by connecting two double rod end actuators in series. It increases the length of actuator but at the same time double load can be handled with same diameter due to twin cylinder design. There was no constraint in terms of length for the space available for mounting of Body Flap actuator so decision was made to use DTLA. All the components of power actuator were sized properly on the basis of stressing calculations. Further all other critical components of EHA system i.e. Electric Motor-Pump unit, Actuator Control Electronics unit, By pass valves and Accumulator are also mounted on the Power Actuator. The dimensions of these components are driven by the sizing calculations performed plus envelope dimensions available of Existing EHA's. ${ }^{11}$ The dimensions from existing EHA's are scaled accordingly to obtain correct dimensions. Further for handling the thermal management issues on EHA, grooved type design is used on the surfaces of Pump, motor, accumulator and ACE to act as heat exchangers. Outer surfaces of these components are made into waves like shape to serve as a radiator as clearly visible in Figure 4.

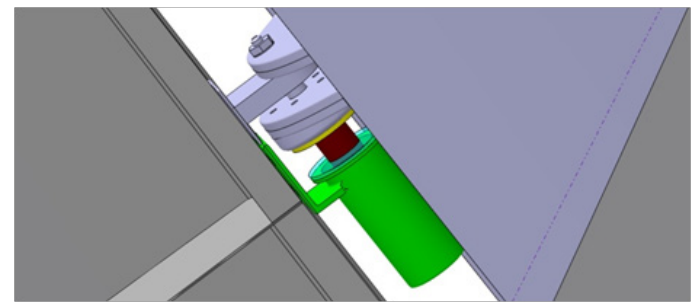

Figure 4CAD model of body flap EHA.

\section{Rudder actuator}

EHA of type Rotary Vane Actuator (RVA) has been used for actuation of Normal/Split Rudder. RVA uses a combination of Fixed and movable vanes to generate torque using hydraulic power. A shaft mounted with movable vanes is assembled inside a cylinder with fixed vanes attached to it. Hydraulic fluid pressure from inlet port rotates movable vanes by required angle generating torque in required direction and subsequently the Control surface attached with Actuator deflects by desired angle. There was very less space available in the gap between Rudder and Fin and also the torque needed to be handled is small so decision was taken to design RVA for this application. Normal and Split rudder which are at the same location as Normal rudder is formed by combination of 2 split rudders. So two RVAs on Table 3 Dual tandem linear EHA for body flap of SL-12 each rudder can easily serve the function of deflection of both normal as well as split rudder. For deflection of normal rudder both RVAs should rotate in same direction whereas for split rudder function, both RVAs need to rotate in opposite directions creating deflection of both split rudders in opposite directions. To achieve the angular stroke required of $\pm 40^{\circ}$, the 3 vanes RVA configuration has been selected for as an optimum design. The CAD model of RVA mounted on Rudder. and Fin is shown in Figure 5

Figure 5 CAD model of RVA mounted on rudder.

\section{Actuation system mass estimation}

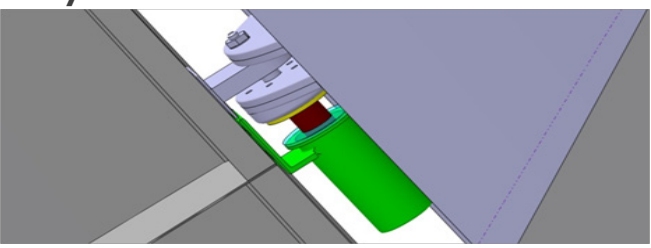

For Mass estimation of components of Actuators, the approach was kept very simple. For the components with known dimensions, mass was calculated from exact values of density and volume and was also confirmed with the CAD models. For the components whose dimensions are not exactly known as detail design was not done for those components, dimensions and mass were evaluated based on literature study for similar items. ${ }^{11}$ To achieve maximum possible weight saving, it was decided to follow minimum reserve factors approach. As per this method the dimensions of components were optimized in a reverse approach based on minimum reserve factor. Especially this approach was used in sizing and mass estimation of Hydraulic Cylinder and Piston. The mass allotted for Hydraulics and Actuation System of SL-12 as per specifications requirement is $196.6 \mathrm{~kg}$. The mass estimated for the complete actuation system was $191.6 \mathrm{~kg}$ which is fully compliant with the mass requirement. The remarkable point is the achievement of this mass limit within the range even after using more actuators than anticipated earlier. This was made possible by the use All Electrical technology of Power by wire actuators.

\section{Specifications of actuators designed}

The complete design specifications of all the actuators were derived based on the stressing calculations of different components parts and detailed specifications of Body Flap Dual tandem linear EHA. The results are tabulated in Table 3.

\begin{tabular}{|c|c|c|c|}
\hline Type & & dem Linear Actuator (EHA) & \\
\hline Total number of actuators & & & \\
\hline \multicolumn{4}{|l|}{ Inputs } \\
\hline Limit Load per DTLA & $133.79 \mathrm{kN}$ & Limit Load per Cylinder & $66.90 \mathrm{kN}$ \\
\hline Angular Stroke & $+20^{\circ} /-30^{\circ}$ & Linear Stroke & $150 \mathrm{~mm}(+60 /-90)$ \\
\hline \multicolumn{4}{|l|}{ Design considerations } \\
\hline Nominal Pressure, Hydraulic system & $\begin{array}{l}27.6 \mathrm{MPa} \\
\text { (4000psi) }\end{array}$ & Effective Pressure inside cylinder & $\begin{array}{l}22.08 \mathrm{MPa} \\
\text { ( } 80 \% \text { of Nominal) }\end{array}$ \\
\hline Ultimate/Proof Factor ratio & 1.40 & Burst Pressure/ Nominal Pressure & 2.5 \\
\hline Piston Rod Dia/ Cylinder Inner Dia & 0.5 & & \\
\hline \multicolumn{4}{|c|}{ Allowable stresses for material (15-5 PH AMS 5659 H 1025) [3] } \\
\hline Yield Strength & $1000 \mathrm{MPa}$ & Young's Modulus, E & 196.5GPa \\
\hline Shear Strength & $669 \mathrm{MPa}$ & Bearing Stress & $1455 \mathrm{MPa}$ \\
\hline
\end{tabular}


Table Continued

\begin{tabular}{llll}
\hline Type & \multicolumn{3}{l}{ Dual Tandem Linear Actuator (EHA) } \\
\hline Detail design specifications & & \\
\hline Piston Rod Dia & $36.42 \mathrm{~mm}$ & Cylinder Inner Dia & $72.87 \mathrm{~mm}$ \\
Piston Rod wall Thickness & $3 \mathrm{~mm}$ & Cylinder wall Thickness & $3 \mathrm{~mm}$ \\
Piston Head Dia & $72.75 \mathrm{~mm}$ & Seal groove width & $10.90 \mathrm{~mm}$ \\
Actuator extended length & $840 \mathrm{~mm}$ & Actuator Neutral position length & $750 \mathrm{~mm}$ \\
Spherical Bearing & RBC I4103-12 & Bearing Dia & $34.925 \mathrm{~mm}$ \\
Bearing Height & $22.22 \mathrm{~mm}$ & Lug height & $16 \mathrm{~mm}$ \\
Bolt Shank dia & $19.05 \mathrm{~mm}(3 / 4 "$ UNF S99 Bolt) & \\
Actuator Envelope Dimensions (Neutral Position) & $749.09 \mathrm{~mm} \times 273 \mathrm{~mm} \times 155 \mathrm{~mm}$ & \\
\hline
\end{tabular}

\section{Conclusion}

By comparing merits and demerits of conventional Hydraulic Actuation and Electric Actuation during Preliminary Research and Design study done by the author, it was concluded that SL-12 has to feature a "Power by Wire" flight control actuation system consisting of Electro Hydrostatic Actuators (EHAs) and Electro Mechanical Actuators (EMAs). Redundancy requirement is very effectively catered in Actuation system architect by maintaining a proper balance between safety and reliability. It is also ensured that the system design is in line with the Airworthiness certification requirements. The most challenging section of the research was the detail designing of actuators and installation on orbiter considering space constraints and other aspects. Nominal Hydraulic pressure of 4000 psi has been used for EHAs to keep an optimum balance between advantages of weight saving and using already developed standard hydraulic equipments (like seals, pump etc) and reducing the development cost and time. Brushless DC Electrical Motor has been used for driving the hydraulic pump of the EHA. 270 VDC Electrical power has been utilized for primary flight control EHAs. Fully compliant Mass estimation results are also very encouraging in bringing forward the point of weight saving made by Power by wire actuators. This technology is surely the future of Actuation technology as a lot of $R \& D$ projects are in progress on All Electric Aircraft concept with the use of EHAs and EMAs for Primary Flight Control.

\section{Acknowledgements}

None.

\section{Conflict of interest}

The author declares that there is no conflict of interest.

\section{References}

1. Smith H. Advanced Space Transportation Reusable Orbiter SL-
12 Project Specification. Department of Aerospace Engineering, Aerospace Design Group, School of Engineering, UK: Cranfield University; 2012.

2. Shuttle Reference Manual. USA: National Aeronautics and Space Administration; 2013.

3. Rice RC, Jackson JL, Bakuckas J, et al. Metallic Materials Properties Development and Standardization (MMPDS). Washington, DC: Department of Transportation Federal Aviation Administration; 2003.

4. NASA Space Vehicle Design Criteria (Structures). Structural Design Criteria Applicable to a Space Shuttle, NASA SP-8057. Washington: National Aeronautics and Space Administration; 1972. 104 p.

5. Certification Specification and Acceptable means of Compliance for Large Aeroplanes. Germany: European Aviation Safety Agency; 2012. $617 \mathrm{p}$.

6. SAE International, ARP 926. Design Analysis Procedure for Failure Modes, Effects and Criticality Analysis (FMECA). Newyork: Society of Automotive Engineers; 1967.

7. SAE International, ARP 4761. Guidelines and Methods for Conducting Safety Assessment Process on Civil Airborne Systems and Equipment. Michigan: Society of Automotive Engineers; 1996.

8. McWhorter LB. Space Shuttle Entry Digital Autopilot. Houston: NASA Johnson Space Center; 2010. 204 p.

9. Lawson CP, Pointon JM. Thermal Management of Electro Mechanical Actuation on an All Electric Aircraft. 26th International Congress of the Aeronautical Sciences; 2008. $11 \mathrm{p}$.

10. Air vehicle Technology. Cranfield Stressing Data Sheets, AVT-AVD 9632. UK: Cranfield University; 2012.

11. Bildstein M. EHA for Flight Testing on Airbus A321: Power Losses of Fix Pump EHA versus Variable Pump EHA. Toulouse: Recent Advances in Aerospace Hydraulics; 1998. 